World Journal of Advanced Research and Reviews
eISSN: 2581-9615 CODEN (USA): WJARAI
Cross Ref DOI: $10.30574 /$ wjarr
JJART

(REVIEW ARTICLE)

Check for updates

\title{
Effect of light on Guinea fowl (Numida meleagris) production: A review
}

\author{
Clement Gyeabour Kyere ${ }^{1,}{ }^{*}$, Korankye Okyere ${ }^{2}$, Addison Duodu ${ }^{2}$, Grace Twumasi ${ }^{2}$, Philip Kwaku Dapaah ${ }^{3}$ \\ and Patrick Atta Poku Jnr ${ }^{1}$ \\ ${ }^{1}$ Department of Science Education, Seventh-day Adventist College of Education, Affiliated to University of Cape Coast, Post \\ Office Box 29, Agona-Ashanti Region, Ghana. \\ ${ }^{2}$ Department of Animal Science Education, Faculty of Agriculture Education, University of Education, Winneba, Post \\ Office Box 40, Mampong-Ashanti, Ghana. \\ ${ }^{3}$ Department of Science Education, St. Teresa's College of Education, Affiliated to University of Cape Coast, Post Office Box \\ 129, Hohoe Volta Region, Ghana.
}

World Journal of Advanced Research and Reviews, 2021, 09(03), 337-345

Publication history: Received on 18 February 2021; revised on 21 March 2021; accepted on 23 March 2021

Article DOI: https://doi.org/10.30574/wjarr.2021.9.3.0115

\begin{abstract}
Artificial light is highly recognized and used in Guinea fowl production. In Guinea fowl production, access to light is an important factor for both growth and egg production. The eye is a vital sense organ under neuro-endocrine regulation in order to allow sight in animals. Guinea fowls perceive light through photoreceptors that transform the energy contained in photons in biological signals. In the eye, the energy of the photons is transformed by photosensitive pigments in the cones and rods of the retina, and transmitted through neurons to the brain where signals are integrated in an image. Photoreceptors in the hypothalamus are biological transformers that convert photon energy into neural impulses. These impulses affect the endocrine system that control ovarian activity in females and therefore, their reproductive behavior. Many physiological and behavioural aspects of Guinea fowl is affected by lightening. Certain essential function of Guinea fowl like body temperature, feeding, metabolism and digestion is directly or indirectly affected by light. Light also controls the activities of different hormones and affects growth maturation and development of organism. The physical activity of Guinea fowls can be affected by daylength, light intensity, colour and wavelength. The increase in physical activity leads to overall development of Guinea fowl. Hence, Guinea fowl producers and breeders must consider light management activities for higher productivity.
\end{abstract}

Keywords:Guinea fowl; Light; Daylength; Light intensity; Wavelength; Neuro-endocrine

\section{Introduction}

The parameters of light that affects Guinea fowl production include intensity, duration, and wavelength which affect physical activity of bird. The increased in physical activity of Guinea fowl improves bone development and improves the health of the bird. Light entering the eyes of Guinea fowls induces response in the hypothalamus which in turn through releasing factor affects the rate of secretion of gonadotropic hormone for the anterior pituitary gland [1] Gonadotropic hormones affect the activity of gonads and in turn the reproductive behavior of Guinea fowls. Physiological and behavioral processes of Guinea fowls are externally controlled by lighting. Among the external factors affecting growth and development light is of major consideration. Color vision of the bird is due to light [2]. Metabolic activities that include feeding and digestion are correlated with lighting. Hormonal activities in bird that control growth, maturation and reproduction are controlled by light. Greater environmental complexity in poultry rearing activities leads to increase in productivity and resolve the welfare concerns [2].

${ }^{*}$ Corresponding author: Clement Gyeabour Kyere

Department of Science Education, Seventh-day Adventist College of Education, Affiliated to University of Cape Coast, Post Office Box 29, Agona-Ashanti Region, Ghana.

Copyright (C) 2021 Author(s) retain the copyright of this article. This article is published under the terms of the Creative Commons Attribution Liscense 4.0. 
Perception of light information in Guinea fowls in the transcranide route is more important than ocular route and that Neuropsin neurons in the paraventicular organ (PVO) contact the cerebrospinal fluid and extend their fibres to the external zone of the median eminence adjacent to the pair tube of the pituary gland, which may translate photoperiodic information into neuro endocrine responses [3]. Birds living in urbanized areas are exposed at night to artificial light and may become more active and extend their feeding period into the night. That is an artificial prolongation of day length can have prolonged effect on the organization of avian life cycle [2].

The major hindrances to Guinea fowl production in Ghana are seasonal changes, nutrition, poor reproductive performance, and lack of proper management practices for efficient production [4]. Guinea fowls are known to be seasonal breeders and therefore, Guinea hens do not lay eggs at certain times of the year due to variation in day length [4]. It is well known that the reproductive performance of layer chickens is affected by day length (Lien et al., 2007). Like any other poultry species such as layer chickens, light is one of the most influential microclimatic factors for growing Guinea fowls, as it greatly influences growth, development and physiological functioning and allows maximum feeding time [5]. According to Lien et al. [6] the year-round production of birds is not possible without proper lighting management; especially with regard to increase in day length. Typical poor egg production during winter is a consequence of insufficient lighting and reduced photoperiodic drive and this can be improve by increase in day length [5].

The objective of the study was to review the effect of lighting on the performance of Guinea fowls.

\section{Methodology}

A desk research was carried out using information from a previous experiment on Daylength/Photoperiod on the performance of local Guinea fowls conducted at the Poultry Unit of the Department of Animal Science Education, University of Education, Winneba, Asante Mampong campus from September, 2016 to December, 2018.

\section{Parameters of Light that Affects Guinea Fowl Production}

\subsection{Light intensity required for Guinea fowls}

Light intensity is one of the most important factors to be considered in all lighting programmes. Low light intensity affects egg production in Guinea fowls. In-order to reduce the incident of light intensity in poultry production a lux meter should be used to precisely determine light intensity in layer house. In the absence of a lux meter a general formula (Light intensity) can also be used to calculate light intensity within a specific area. Light intensity at a particular point depends on the distance between the light sources to the point of interest. The minimum light intensity required for maximum egg production is 5.38 lux in dark houses for Guinea fowl layers [4]. According to Lewis et al. [7] in opensided houses, 10 lux is needed to provide sufficient light intensity to enhance egg production. Daily period of 14 hours of light is required for optimum egg production and that more than 17 hours of day length negatively affect egg production in Guinea fowl. Light radiation within the visible spectrum range of 664-740 $\mathrm{nm}$ and therefore the lamps used in layer houses should emit light within this range.

\subsection{Light duration/photoperiod required for Guinea fowls}

Lighting duration that is photoperiod is the second major aspect of light that affects Guinea fowl productivity. Lighting length is generally dependent upon the age of Guinea fowls and the type of housing in used. Natural daylight, quite intuitively, is considered to be the best and optimal lighting for Guinea fowls. However, Guinea fowls need to be provided six hours of sleep during the starter period, but, may require higher hours at certain points of growing stage. Guinea fowls align their activities to the appropriate time of the day and year through the stimulation of photoreceptors by daylight, which synchronizes their internal circadian and circannual clocks. Research interest in the biological impact of artificial light at night has grown in recent years and options to reduce the effects of night-time light pollution on ecosystems are being investigated [8].

\subsection{Constant light for Guinea fowls}

Guinea fowls are healthier, look better, and may behave better if they are exposed to natural or full spectrum light (with ultraviolet light - UVB) on a daily basis. Natural sunlight or full spectrum lighting with UVB is necessary for a bird to synthesize vitamin $\mathrm{D}$, which is essential for the proper regulation of calcium and phosphorus levels in the body [9].Like humans, birds are complex animals that depend on lighting to regulate and signal various biological processes [10].Guinea fowls oftentimes receive insufficient light, or the wrong type of lighting, which can be detrimental to their 
health. The majority of constant supply of artificial lighting is designed by profit-seeking businesses that strive to produce as much perceived brightness as possible using as little electricity and manufacturing cost as possible. As a result, light quality, whether measured through spectrum analysis, is almost never a priority. Constant lighting should be considered to be more than just a tool that facilitates human vision, but an essential component and building block for avian health, taking a serious look at high quality full spectrum lighting is absolutely critical $[11,12]$.

\subsection{Colour of light}

The colour of light used in Guinea fowl production has significant effect on the performance of the bird. Guinea fowls are UV sensitive and most birds perceive colors through 4 single cone types. Also, they have extra-ocular light perception through photoreceptors in the pineal gland and brain measured the spectral absorption characteristics of the photoreceptors in the eyes of the bird, which are similar to those described in other poultry birds [2,14]. Using lamps with different spectra would therefore have different effects on birds simply because some colors are perceived as less intense [15].Birds sense light through their eyes and through photo sensitive cells in the brain. Blue light weight stimulates growth in chickens while orange red stimulates reproduction. Guinea fowls have variety of diversifications to their color equipment not shared by humans. The use of modern light-emitting diode (LED) lamps in outdoor lighting has economic advantages, but, more importantly, their color compositions can be custom designed, potentially mitigating the impact of light on flora and fauna through adaptation of the spectrum [2]. The Color Rendering Index (CRI) measures the ability of a light source to bring out the true colors of an object. It is the spectral qualities of a light source that determine its color rendering abilities [2, 15]. Full spectrum light sources, by virtue of being similar to natural daylight, must have a very high CRI to be considered a true, full spectrum light source. Ultimately, it should be possible to advise the use of lamps with certain characteristics (such as spectral composition and light intensity) for a specific setting, in such a way that the emitted light has sufficient quality to support human activities while having minimal effects on the biological processes of the Guinea fowls. Guinea fowls under red or white light became significantly heavier than blue and green light zone. White light accelerates muscle growth at an early age as compared to red light.

\subsection{Wavelength}

Guinea fowls are sensitive to a range of wavelengths to which humans are blind. Light of various wavelength has varied stimulatory effects on the tissue layer and might end in activity changes that may have an effect on growth and development of the bird [2,15].Light-emitting diode (LED) phosphors are the technological advancement in LED lighting technologies that makes full spectrum lighting possible. Phosphors convert light energy of one wavelength and redistribute that energy as a different wavelength [16]. For example, a red phosphor will convert blue light energy, and re-emit red wavelength energy. By carefully adjusting the amount of various colored LED phosphor in an LED chip, an unprecedented level of spectral control becomes possible. Because LED phosphors are in powder form, they can be readily mixed into various color recipes with changes in phosphor ratio resulting in subtle color differences [2, 16]

\subsection{Darkness requirement for growers}

Guinea fowl varieties originate from tropical areas. There, they usually experience 12 hours of daylight and 12 hours of darkness. The birds require more sleep as compared to humans and most continue to need at least 10 hours of sleep time daily. Lights and activity will keep a bird awake, since his instincts are to stay awake during this time when predators may be present. The bird may be able to sleep while there is noise, but movement will keep it on the alert [2, 13]. Study has shown that darkness is as vital to growth and health of broilers as light-weight. Darkness (12 hours) during the first 8 weeks affect feed intake and steady growth. Guinea fowls reared under longer periods of light are found healthier than under long darkness conditions.

\section{Effect of Lighting in Guinea Fowl (Numida meleagris) Production}

\subsection{Effect of light on fertility and hatchability}

Guinea fowl start to lay in the beginning of the rainy season and continues laying throughout the rainy season. The egg laying period can be extended and early fertility improved by using artificial lighting. Decrease in day length affect testicular development which results in infertility in Guinea fowl cocks [19]. Light is the primary factor which induces sexual activity in pheasant, quail and chicken [5]. Increasing light in Guinea fowls enhances gonadal development in males which increase fertility and hatchability. Decrease in day length affects early maturity. Delay in maturity due to insufficient lighting affects fertility, hatchability and subsequent growth performances in Guinea fowls[5]. Insufficient light in Guinea fowls affects the production of progesterone and testosterone in males. Ovulation in Guinea fowls depends on hormonal mechanism that is closely related to external factors such as artificial light, feed and water supply. 
Increases in day length or sufficient light regimes ensure adequate production of hormones such as follicle stimulating hormone (FSH) and Luteinizing hormones (LH)[12].These hormones allow ovulation to occur regularly during laying [8]. Layers are most sensitive to light between 11 and 15 hours after the light is turned on. During this photosensitivity phase, follicle stimulating hormone (FSH) and Luteinizing hormones (LH) stimulate ovulation and controls the reproductive functions. Increase in day length between 15 to 18 hours increase fertility and hatchability [11]. McDaniel et al. [13] also reported that increases in photoperiod increase fertility and hatchability in chicken.

\subsection{Effect light on growth parameters}

Light has a great impact on health, growth and reproduction among Guinea fowls. Newly hatched keets that do not get enough light usually have problems finding the water and feeding through at night, which can lead to an increase in mortality due to malnutrition. Poultry birds as well as mammalian species respond to light energy in a variety of ways, including growth and reproductive performance [2]. Short day lengths and feed restriction during the production periods delays sexual maturity and reduce growth and body weight in poultry birds [14]. Ahsanet al. [14] reported that, light influence feed and water intake in poultry production. The advantage of a longer daily light period in Guinea fowl production is that, it increases feed and water consumption and in turn increases growth and body weight. If the daily exposure to light is less than twelve hours it can lead to reduce feed and water intake which subsequently affect growth and reproduction.

Day length is reported to determine the period in which daily activity and feeding can occur and affects feed intake and body weight gain in birds [15]. Longer photoperiod is related to both higher energy intake and energy expenditure level, resulting in larger weight gain [14]. Net weight gain is the result of a positive balance between energy intake and energy expenditure. Feed intake in Guinea fowls reared on natural light and increasing day length had best feed conversion efficiency while those in decreasing light had significantly poor feed conversion efficiency.

The age at sexual maturity is although genetically determined, yet some manipulations can be done by photoperiod. Avian species utilize a variety of reproductive strategies that allow them to reproduce under a diversity of conditions and environments. The most important factor regulating the development of reproductive capacity in Guinea fowl is photoperiod. Lewis et al. [7] reported that time required to reach maturity weight of breeder chicken increased proportionally with photoperiod. Birds in longer photoperiod consumed more feed and were heavier at sexual maturity than shorter day length. However, exposure to continuous light of 23L: 1D showed detrimental effect on weight gain and number of days to sexual maturity.

In a study conducted by Korankye [20] age at first egg was significant $(\mathrm{p}<0.05)$ influenced by day length. The most efficient daylength was observed to be 18L: 6D with females reaching sexual maturity at 151 days and the less efficient was recorded in 12L: 12D with 180 days. Mean age at sexual maturity of 165.25 days was obtained and was lower than 12L: 12D, 14L: 10D and lower than 16L: 8D and 18L: 6D. Varied day length, similarly, had significantly ( $p<0.05)$ effect on egg weight at first egg. The highest $(\mathrm{p}<0.05)$ was recorded in 18L: 6D whilst 12L: 12D recorded the lowest. Mean egg weight at first egg of $28.36 \mathrm{~g}$ was observed.

Age at first egg was linearly affected by increased day length. Age at first egg was improved by day length change from 12L: 12D to 18L: 6D [7]. This result show that age at first egg and laying peak advanced with increased day length during the transition. These findings are consistent with Lewis et al. [7] who showed that transferring pullets shorter to longer day length tends to stimulate ovarian activity, whereas, transferring pullets from longer to shorter day length suppresses ovarian activity. Lewis et al. [7] suggested that plasma LH and FSH concentration during the rearing period might be useful predictors of sexual maturity and egg production rate in chicken and their secretions are influenced by day length regimen. The report of this study was corroborated by Lewis et al. [7] who reported that there is a difference in age at 50\% egg production between a flock transferred to 11 or $12 \mathrm{~h}$ followed by further increases to 15 or $16 \mathrm{~h}$.

\subsection{Effect of light on egg characteristics}

Guinea fowl eggs provide nourishment and protection to the developing keets, therefore the quality of the egg is important for the hatchlings. Environmental modification such as increases in day length influenced the quality of Guinea fowl eggs. Kyere et al. [5] reported that haugh unit, egg diameter, yolk weight, albumen height and albumen weight are not influenced by light. Kyere et al. [5] observed that yolk height, shell weight and shell thickness are influenced by different lightning regimes. Similarly, [5] reported that an increase in day length reduces shell weight and shell thickness. They further explained that small size eggs have higher surface to volume ratio which reduces shell weight and thickness. It has been demonstrated that a short daily photoperiod of less than 12 hours has a negative influence on the laying rate. Light duration has widely been used for the improvement of the reproductive performance of layers [2]. Utshav [2] indicated that lighting is a powerful exogenous factor in control of avian physiological and 
behavioural processes. Photoperiod is a factor that influences the behaviour and egg quality of Guinea fowl laying hens. There is a complex interaction between the circadian system, photoperiod time measurement, activation and regulation of the neuro-endocrine system regulating reproduction and hormonal action [2].

The study of Lewis et al. [7] indicated that birds on photoperiod of 11,13, and 14 hours produced eggs during the laying period up to 68 weeks of age than birds maintained on 10 hours. The study indicated that layers maintained on 16 hours produced the fewer eggs in broiler breeders. Boon et al. [15] found that extreme long light regime of 20 hours induces less egg production in quails. In temperate climates, lighting duration has been reported to affect various performance parameters such as spermatogenesis, egg production, body weight and feed efficiency. Lewis, et al. [7] in their study on effect of constant photoperiod on laying performance of breeders reported that longer photoperiod birds had inferior rate of lay in the first half cycle but, superior in the second cycle, which together with the photoperiod effect on maturity resulted in bird on 11,13, or 14 hours producing most eggs up to 68 weeks and those on 16 hours produce fewest. The report explained that pattern of egg production was due to photo refractoriness causing a mid-cylce pause and then spontaneously resuming egg production.

Internal and external egg quality is influenced by Guinea fowl nutrition on protein and energy, available light, system of production and storage. Hesham [17] demonstrated three different photoperiod $(13,16$, and 19) on egg quality. Birds housed in 16 hours day length laid egg with significant higher external quality traits than those reared in 13 hours day length. Internal quality trait, including yolk height, albumen height, yolk weight and yolk rating were significantly higher in 16 hours day length than 13 hours [17]. External egg quality is determined by shell colour, thickness and weight, cleanliness, integrity (cracks/strengths) and shape.

\subsection{Effect of light on haematological and biochemical parameters}

The blood contains several metabolites which provide useful information on nutritional status and clinical investigation of an individual hence WHO recommended the use of blood parameters for medical and nutritional assessment [18]. Serum biochemical and haematological reference values are used to establish normality and to diagnose disease and physiological alteration [19]. Textbook reference intervals produced by European or United States veterinary laboratories are often based on animals living under good husbandry conditions. The importance of haematological and biochemical parameters as diagnostic tools and physiological indicators in birds has been documented [19]. Haematological parameters were used extensively in avian medicine as physiological indicators and disease diagnostic tools [20]. The differences in haematological values among local chickens reared in different regions potentiate its investigation to diagnose the health status of the birds. The information gained from investigation of haematological values, disease diagnosis and managerial factors are the main tools for developing new lines of birds which are genetically able to resist different diseases [21]. Sex, age and nutrition are the major factors affecting avian hematology [20]. Haematological and biochemical values were reported in many species of birds, particularly African and Asian reared chicken during hot season [21].

Serum chemistry analyses also have been used to experimentally characterize the three metabolic phases associated with long-term fasting in geese and penguins [22]. Serum protein concentrations reflect protein synthesis and degradation and were found to decline in greater snow geese during prolonged feed deprivation [22]. Serum chemistry variables also can be used to evaluate infectious diseases in birds (Hochleithner, 1994). Recent publications on biochemical parameters of the Guinea fowl include Iddrisu [23] (Total serum protein, $67.30 \mathrm{~g} / \mathrm{L}$; albumin, $31.03 \mathrm{~g} / \mathrm{L}$, globulin, 36.29 and cholesterol, $3.40 \mathrm{mmol} / \mathrm{L}$ ), Gholipour et al. [24] (Total serum protein, $52.1 \mathrm{~g} / \mathrm{L}$; albumin, $42.1 \mathrm{~g} / \mathrm{L}$ and cholesterol, $2.57 \mathrm{mmol} / \mathrm{L}$ ) and Obese et al. [25] who compared biochemical parameters of Indigenous and exotic Guinea fowls as follows: albumin $(29.87 \pm 0.96$ versus $27.08 \pm 0.95 \mathrm{~g} / \mathrm{L})$ and total cholesterol $(4.79 \pm 0.14$ versus $2.99 \pm$ $0.14 \mathrm{mmol} / \mathrm{L})$.

The normal haematological and plasma biochemical parameters of several avian species have been reported; these include the White England turkey [26] and Guinea fowl [27] Haematological values of male Guinea fowls have been recorded for males and females, respectively, as follows: Haemoglobin $(14.2 \pm 3.30$ and $12.4 \pm 1.71 \mathrm{~g} / \mathrm{dL})$, Erythrocyte count $(2.65 \pm 0.54$ and $2.44 \pm 0.431012 / \mathrm{L})$, Mean Cell Haemoglobin Concentration $(34.3 \pm 5.70$ and $32.4 \pm 4.20 \mathrm{~g} / \mathrm{dL})$, Lymphocytes $(79.7 \pm 16.10$ and $80.1 \pm 15.60109 / \mu \mathrm{l})$, Leucocytes count $(22.4 \pm 10.26$ and $21.42 \pm 10.71109 / \mu \mathrm{l})$ ) and Heterophil $(16.5 \pm 7.02$ and 15.6 $\pm 6.90109 / \mu \mathrm{l})$ ) [28]. Strakovaet al. [29] reported of Red blood cell $(2.15 \pm 0.451012 / \mathrm{L})$, Haemoglobin $(12.91 \pm 4.28 \mathrm{~g} / \mathrm{dL})$, PCV $(36.00 \pm 0.04 \%)$, Leucocytes $(14.35 \pm 3.16109 / \mu \mathrm{l})$, Neutrophil $(2.58 \pm 1.06109 / \mu \mathrm{l})$ and Lymphocytes $(116.01 \pm 2.78109 / \mu \mathrm{l})$. The study of Obese et al. [25] compared the haematological parameters of Indigenous and exotic helmeted Guinea fowls as influenced by age and reported that Total RBC counts $(1.89 \pm 0.05$ versus $\left.1.64 \pm 0.05 \times 10^{12} / \mathrm{L}\right), \mathrm{PCV}(37.04 \pm 0.77$ versus $33.47 \pm 0.76 \%)$, and WBC counts $(3.51 \pm 0.15$ versus $2.57 \pm 0.14$ $\left.\times 10^{9} / \mathrm{L}\right)$ were higher $(\mathrm{P}<0.05)$ in the indigenous than exotic. 
Light is one of the management techniques used in Guinea fowl production to enhance the productivity of meat and eggs [30]. Several earlier studies have compared the effect of different lighting regime programmes on the health status in broiler chicken. Follet and Robinso [8] reported that different light restriction programmes in broiler chicken production significantly decreased total serum protein and cholesterol in poultry birds. Royter et al. [21] reported that light had little influence on hemoglobin, red blood cells, white blood cells, packed cell volume, neutrophil, lymphocytes, eosinophil, total serum protein, albumin, globulin and cholesterol. Korankye et al. [31] reported that day length above $17 \mathrm{hrs}-20 \mathrm{hrs}$ resulted in photo refractoriness in layers [32] Lack of any difference in cholesterol level may be due to the same diet and same usage of energy in the intensive system of the experimental animals [33].

\subsection{Effect of light on Guinea fowl reproductive hormones}

Artificial lighting is a tool commonly applied to stimulate egg production. The levels of luteinizing hormone (LH) and follicle stimulating hormone (FSH) increased within a single day of exposure to long hours of photoperiods. Egg production in Guinea fowl increased with increasing day length [7]. Increases in day length leads to an increase in luteinizing hormone (LH) secretion and this will ensure that the hen will lay eggs early and continue to lay eggs. Guinea fowl layers should be given artificial light during the grower stage. The hens are photo-stimulated and lay eggs earlier than hens with short day length. Guinea fowl layers that are provided with artificial light between 16 hours and 18 hours are able to lay eggs earlier as compared to layers with short day length. Light stimulates the hypothalamus to increase the secretion of gonadotropin-releasing hormone (GnRH) [34]. GnRH induces a release of luteinizing hormone (LH) and follicle stimulating hormone (FSH) from the pituitary gland. In Guinea fowls, FSH stimulates the growth of immature follicles while a rapid increase in LH stimulates ovulation. When LH levels increase in plasma it triggers the release of progesterone from the granulose cells in the follicles of the ovary. This occurs through a positive feedback mechanism between LH and progesterone. The plasma concentration of LH increases to its highest peak, this make the largest follicle ovulates. An increase in day length enables early egg production and ensures that the birds will lay continuous at a lighter body weight. For Guinea fowl breeders to achieved maximum egg production, 16 hours light is needed during peak egg production period. Decreased in day length during laying period seriously affects egg production [30].

In Guinea fowl, plasma LH and FSH concentration are directly related to different patterns of photo-stimulation [30]. There is a direct relationship between concentration of plasma LH and the duration of pulse of light given to breeder hens kept under 8L: 16D. It seems likely that concentration of plasma LH and FSH could be used to establish reproductive function of domestic chicken. Dunn and Sharp [35] concluded that the shortest photoperiod needed to stimulate maximum release of LH was between 10.5 hours and 12.75 hours and for maximum egg production, between 12.75- 15.25 hours [8]. Both plasma FSH and LH concentrations increase in juvenile female chicken after photostimulation. Photo-stimulation advance sexual maturation by increasing gonadotropin secretion, particularly FSH which stimulates ovarian follicular development. Lewis et al. [7] studied the age related rate of change to an increment in photoperiod in poultry and the study concluded that there was an increase in LH following photo-stimulation. At age 58 weeks, LH was higher for birds supplied with 11-16 hours than those of constant 8 hours.

Increased day length has been observed to increase thyroid hormone secretion to aid metabolism which is required for the initiation and maintenance of egg production [36]. In a study conducted by Korankye [35] day length revealed no significant difference in all hormonal parameters measured except prolactin and testosterone. The results contradict the earlier report that increasing day length results in photo stimulation which induces the hypothalamus to release GnRH which facilitates the production of Follicle Stimulating Hormone and Luteinizing Hormone [37]. However, value of prolactin is supported by earlier report that increasing day length increases prolactin secretion and decrease follicle stimulating hormone, luteinizing hormone, progesterone and estrogen [35]. Rozemboim et al. [38] however, reported of no significance difference. Prolactin hormone secretion is the responsibility of nocturnal melatonin secretion which increases in period of darkness and in photo refractoriness and has the consequence of ovarian regression and broodiness $[39,40]$.

\section{Conclusion}

This study concludes that light management in Guinea fowl production is very vital to promote healthy growth and improved laying performance. Daylength/photoperiod, wavelength and light intensity are very important parameters which influenced Guinea fowl production. Whereas, exposure of Guinea fowls to 12 hours of darkness affect the health of the bird, reduced egg laying and the overall performance of the bird. It is very important to understand how light affects Guinea fowl production. More importantly Guinea fowl breeders need to have proper light management practices during the starter, grower and breeder stage. Many farmers and breeders might not be experiencing the complete result of restricted light weight regimes as a result of the programs don't seem to be applied systematically. 


\section{Compliance with ethical standards}

\section{Acknowledgments}

The authors are grateful to the Department of Animal Science Education, Faculty of Agriculture Education, University of Education, Winneba for providing facilities for this study.

\section{Disclosure of conflict of interest}

Authors have declared that, no conflict of interests exist.

\section{References}

[1] Egbunime IC, Ayo JO. Physiological need of avian eyes in light perception and their response to photoperiodicity. Journal of World Poultry Science. 2016;72(3): 605 - 614.

[2] Utshav P. Effect of Lighting in Broiler Production. Acta Scientific Agriculture.2019; 3(6): 114-116.

[3] Bentley GE, Goldsmith AR, Dawson A, Briggs C, Pemberton M. Decreased light intensity alters the perception day length by male European starlings. J. Bio. Rhyt. 1998; 13:148-158.

[4] Kyere CG, Okyere K, Duodu A, Twumasi G, Dapaah PK. Effect of different lighting regime on growth and reproductive performance of the Guinea fowl (Numida meleagris). World Journal of Advanced Research and Reviews. 2020; 07(02): 294-302.

[5] Kyere CG, Annor SY, Kagya-Agyemang JK, Korankye O. Effect of egg size and day length on reproductive and growth performance, egg characteristics and blood profile of the Guinea fowl. Livestock Research for Rural Development. 2017;29.

[6] Lien RJ, Hess JB, McKee SR, Bilgili SF, Townsend JC. Effect of light intensity and photoperiod on live performance, heterophil-to-lymphocyte ratio, and processing yields of broilers. Poultry Science. 2007; 86: 1287-1293.

[7] Lewis PD, Danisman R, Gous RM. Photoperiodic responses of broilers. III. Tibial breaking strength and ash content. British Poultry Science. 2009; 50: 673-679.

[8] Follet BK, Robinso JE. Photoperiod and gonadotropin secretion inbirds. In "Progressin Reproductive Biology"(R.J.ReiterandB.J. Follett, Eds.). 1980; 5: 39-61. Karger, Basel.

[9] Han S, Wang Y, Liu L, Li D, Liu Z, Shen X. Influence of three lighting regimes during ten weeks growth phase on laying performance, plasma levels and tissue specific gene expression of reproductive hormones in Pengxian yellow pullets. 2017; PLoS ONE 12(5): e0177358.

[10] Han S, Wang Y, Liu L, Li D, Liu Z, Shen X, Xu H, Zhao X, Zhu Q, Yin H. Influence of three lighting regimes during ten weeks growth phase on laying performance, plasma levels- and tissue specific gene expression- of reproductive hormones in Pengxian yellow pullets. PLoS ONE. 2017; 12(5): e0177358.

[11] Jesuyon OMA, Salako AE. Effect of Seasons on the Reproductive Performance of Bovan Nera and Isa Brown Parent-stock Chickens in a Hot Humid Environment. International Journal of Animal and Veterinary Advances. 2012; 5(6): 212-21.

[12] Jayarajan S. Seasonal variation in fertility and hatchability of chicken eggs. Indian Journal of Poultry Science. 1992; 27(1): 36-39.

[13] McDaniel CD, Brament RK, Wilson JC, Hawuth B. Fertility of male and female broiler breeders following exposure to elevated ambient temperature. Journal of Poultry Science.1995; 75: 1029-10.

[14] Ahsan VH, Nazir A, Shalid R, Shah TH. Effect of Light and Feed Restriction during Rearing or Production Performance of Egg Strains Layers. Asian- Australian Journal of Animal Science. 1997; 10(6):657-664.

[15] Boon P, Visser GH, Daan S. Effect of photoperiod on body weight gain and daily energy intake and energy expenditure in Japanese quail (Coturnix. C. Japonica).Journal of Physiology and Behavior. 2000; 70:249-260.

[16] Dunn IC, Sharp PJ. Photoperiodic requirement for LH release in juvenile broiler and egg-laying strain of domestic chicken feed and libitun or restricted diets. Journal of Reproduction and Fertility. 1990; 90:329-335. 
[17] Hesham, HM. Effect of different photoperiod on same maintenance behavior, external and internal egg quality traits of layers. Japanese Journal of Veterinary Research. 2016;64(2):139-142.

[18] World Health Organization Technical report series. No.842 (Expert committee on medical assessment and nutritional status). WHO, Geneva. 1963.

[19] Kusina, JF, Muchenje V. Biodiversity, conservation and sustainable development in the mid-Zambezi Valley. Action 5. Micro projects feasibility study in small animal breeding inAngwa, Neshangwe-Gonono, Guruve, Zimbabwe, (University of Zimbabwe). 1999.

[20] Harr KE. Clinical chemistry of companion avian species: A review. Veterinary Clinical Pathology. 2002; 31:140151.

[21] Ladokun AO, Yakubu A, Otite JR, Omeje JN, Sokunbi OA, Onyeji E. Haematological and serum biochemical indices of naked neck and normally feathered Nigerian indigenous chickens in a sub humid tropical environment. International Journal of Poultry Science. 2008; 7: 55-58.

[22] Robin JP, Cherel Y, Girard H, Geloen A, Maho LY. Uric acid and urea in relation to protein catabolismin long-term fasting geese. Journal ofComperativePhysiology. 1987; 157:491-499.

[23] Iddrisu A. Growth response of guinea fowl fed diets containing Bovine blood blended with cassava. Master's Thesis. Kwame Nkrumah University of Science and Technology. Ghana. 2014.

[24] Gholipour V, Chamani M, Shahryar HA, Sadeghi A, Afshar MA. Effects of Dietary L-glutamine Supplement on Performance, Egg Quality, Fertility and Some Blood Biochemical Parameters in Guinea Fowls (Numida meleagris). Journal of Kafkas University VeterinaryScience. 2017;23(6): 903-910.

[25] Obese FY, Zoudi SA, Naazie A, Ayizanga RA. Effect of age, breed and sex on haematological and blood biochemical parameters in helmeted guinea fowl (Numida meleagris). Comparative Clinical Pathology. 2018.

[26] Makinde MO, Fatunmbi OO. Some haematological and biochemical values of Turkeys in Ibadan. Journal of Bulletin AnimalHealth Production Africa. 1985; 33: 245-248.

[27] Oyewale J0, Ogwuegbu SO. Hematological studies on the Guinea fowl (Numida meleagrispallas). Journal ofBulletin Animal Health Production Africa. 1986; 34:61-65.

[28] Nalubamba KS, Mudenda NB, Bwalya EC, Masuku M, Munyeme M, Munang'andu HM. Seasonal variations in health indices of free-ranging asymptomatic guinea fowls (Numida meleagris) in Zambia. Asian Pac.Journal of TropicalMedecin. 2014;7(1): 143-149.

[29] Straková E, Suchý P, Kábelová R, Vitula F, Herzig I. Values of Selected Haematological Indicators in Six Species of Feathered Game. ACTA VET. BRNO. 2010; 79:3-8.

[30] Korankye 0, Kagya-Agyemang JK, Annor SY, Asabere-Ameyaw A, Kyere CG. Effect of Day Length and Seasonal Variation on Haematological, Biochemical and Hormonal Traits of Indigenous Guinea fowl (Numida meleagris) in Ghana. Journal ofAnimal Research. April 2018; 8(2): 1-08.

[31] Okyere K, Kagya-Agyemang JK, Annor SY, Asabere-Ameyaw A, Kyere CG. Effects of season, graded dietary protein and artificial insemination on semen characteristics and reproductive performance of indigenous Guinea fowl (Numida meleagris). Bulletin of Animal Health and Production in Africa. 2020; 68: 251-261.

[32] Lewis PD, Gous RM. Effect of Constant Photoperiod on the laying performance of broiler breeders allowed conventional or accelerated growth. Journal of Agriculture Science. 2006; 143(1):97-108.

[33] Obinna OVM, Ogunda UE, Ogbuenu IP, Obikaonu H, Emenyonu C. Effect of sex and System of Production on haematological and Serum Biochemical Characteristics of Helmeted Guinea fowl in South Eastern Nigeria International Journal ofBioscience. 2011; 1(3):51-56.

[34] Korankye 0 . Influence of day length and dietary protein concentration on production, reproductive traits and blood characteristics of indigenous guinea fowl (numida meleagris) in Ghana. A thesis submitted to the school of graduate studies, University of Education, Winneba, in partial fulfilment of the requirements for the award of Doctor of Philosophy in Animal Science (Reproductive Physiology). 2018.

[35] Dunn IC, Sharp PJ. PhotoInduction of Hypothalamic Gonadotrophin Releasing Hormone-I mRNA in the Domestic Chicken: A Role for Oestrogen? Journal of Neuroendocrinology. 2001; 11(5):371-375.

[36] Royter Y. Breeding work with guinea fowl (in Russian). Ptisevodstvo. 1991; 12:36-38. 
[37] Opel H, Proudman JA. Effect of repeated handling and blood sampling on plasma levels in young turkey. Journal ofPoultry Science. 1982; 61: 1390-1398.

[38] Rozemboim I, Tako E, Gal-Garber OA, Proudman JA, Uni Z. The effect of heat stress on Ovarian Function of laying hens. Journal of Poultry Science. 2014; 86(8):1760-65.

[39] Reddy IJ, David CG, Sarma PV, Singh K. The Possible Role of Prolactin Secretion in Domestic Chicken GenneralComperativeEndocrinology. 2002; 127:549-557.

[40] Kagya-Agyemang JK, Shendan S, Yinzuo B. Studies on the endocrine and neuroendocrine control of broodiness in the yuchuanghen.InternationalJournal of Poultry Science. 2012; 11:488-515. 